\title{
Reseksjon i proksimale falang ved hammertå
}

\begin{abstract}
Sammendrag
Bakgrunn. Hammertå er en av flere tådeformiteter som skyldes ubalanse mellom senene som bøyer og strekker tærne. Tilstanden rammer flest kvinner og kan skyldes systemsykdom, men er hyppigst idiopatisk. Standard operasjonsmetode er reseksjon av distale del av proksimale falang. Formålet med undersøkelsen var å vurdere våre resultater etter operasjon for hammertå ved St. Olavs hospital.
\end{abstract}

Materiale og metode. Etter gjennomgang av journaler hos hammertåopererte ved St. Olavs hospital i perioden 1999-2004 innhentet vi de operertes vurdering av inngrepet gjennom et utsendt spørreskjema. Pasienter som fortsatt hadde plager ble innkalt til en klinisk etterkontroll.

Resultater. 141 pasienter var operert for hammertær i perioden. 131 besvarte det utsendte spørreskjemaet. Oppfølgingstiden var gjennomsnittlig fem år (spredning 3-8). $86 \%$ var kvinner, og gjennomsnittsalderen ved operasjonstidspunktet var 65 år. I alt $25 \%$ av de opererte oppga å ha et dårlig resultat etter primæroperasjonen. $41 \%$ av de misfornøyde pasientene som møtte til kontroll hadde hyperekstensjonsstilling i grunnleddet i tillegg til fleksjon i midtleddet.

Fortolkning. 25\% misfornøyde pasienter anser vi som en for høy andel. Tillegg av hyperekstensjonsstilling i grunnleddet er en mer omfattende deformitet og krever annen operativ metode enn standardoperasjonen. Våre tall tilsier at andelen misfornøyde pasienter kan reduseres noe ved god preoperativ differensiering av «krøllete tær».

\section{Grethe E. Borchgrevink}

grethe.borchgrevink@stolav.no

Ortopedisk avdeling

St. Olavs hospital

7006 Trondheim

\section{Vilhjalmur Finsen \\ Ortopedisk avdeling \\ St. Olavs hospital}

og

Det medisinske fakultet

Norges teknisk-naturvitenskapelige universitet Trondheim

Hammertå (fleksjonskontraktur av midtleddet) er den vanligste feilstillingen i de fire laterale tærne. Den skiller seg fra klubbetå (fleksjonskontraktur i ytterleddet) og klotå (fleksjonskontraktur i begge disse leddene og i tillegg hyperekstensjon i grunnleddet og ofte kallositeter under metatarshodet plantart). Valg av operasjonsmetode er avhengig av typen feilstilling og om feilstillingen er fleksibel eller ikke.

Årsaken til feilstillinger i tærne er ubalanse mellom intrinsisk og ekstrinsisk muskulatur. Tilstanden er vanligvis idiopatisk, men kan også skyldes systemiske lidelser som diabetes, revmatoid artritt og nevrologiske sykdommer (1). En annen årsak til utvikling av feilstillinger i tærne er svakhet i musculus tibialis anterior eller stram akillessene $(2,3)$. Under disse forholdene vil ekstensor digitorum longus-senen brukes som hjelper for å dorsalflektere i ankelen. Ved slik økt bruk av ekstensorsenen vil ekstensjonen i grunnleddene kunne tilstivne permanent. Utviklingen av tilstanden skjer gradvis, og den er hyppigst i 60-70 års alder $(1,4)$. Det er flest kvinner som utvikler hammertær $(1,4,5)$.

Hammertær kan la seg rette ut passivt og derved være fleksible, eller de kan være fikserte. Hos yngre pasienter med fleksible hammertær anbefales konservativ behandling, eller en leddbevarende korreksjon ved å transponere fleksor digitorum longus-senen til ekstensorsenen over proksimale falang (3, 6). Fikserte hammertær opereres oftest ved å forkorte skjelettet og de dorsale bløtdelene med en subkapital reseksjon av proksimale falang og avstivning i mellomleddet $(5,7,8)$. Rapporterte sekveler etter hammertåoperasjoner er feilstillinger, smerter, nummenhet, løs tå som ofte kan legge seg skeivt, kosmetiske plager og metatarsalgi $(5,9,10)$.

Ved St. Olavs hospital har vi operert de fleste pasienter med hammertær med resek- sjon av distale del av proksimale falang. Hensikten med denne studien var å vurdere resultatene av dette inngrepet med hovedvekt på pasientens subjektive plager og klinisk vurdering på middels lang sikt.

\section{Materiale og metode}

Prosjektet ble lagt frem for Regional etisk komité for medisinsk og helsefaglig forskningsetikk som en evalueringsstudie, og den ble ikke funnet fremleggingspliktig. Pasientdata er registrert i en ikke-personidentifiserbar form, og prosjektet er godkjent av Personvernombudet.

Gjennom det pasientadministrative systemet til St. Olavs hospital fant vi 164 personer som var operert for hammertær (ICD-10 kode M20.4) i seksårsperioden 1999-2004. Alle journalene ble gjennomgått av forfatterne. Preoperative vurderinger, operasjonsmetode og postoperative kontroller ble gjennomlest og det ble lett etter relevante bidiagnoser som kunne disponere for feilstillinger i tærne. 14 pasienter var døde. Én pasient var ikke i stand til å svare. Vi ekskluderte de åtte pasientene som var operert for definert klubbetå eller operert med bløtdelsplastikk. Reseksjon av distale del av proksimale falang inngikk i operasjonsmetoden hos de resterende 141 pasientene som ble tilsendt et spørreskjema høsten 2007. Gjennomsnittlig oppfølgingstid var fem (3-8) år. Vi mottok etter to purringer svar fra totalt 131 pasienter operert for 170 hammertær. Disse utgjør materialet i denne studien.

Deskriptive pasientopplysninger, operasjonsbeskrivelse og opplysninger om postoperativ kontroll, samtidige fotinngrep og bidiagnoser med relevans for hammertådiagnosen og opplysninger om eventuell reoperasjon ble hentet fra journalene. Følgende bidiagnoser ble vurdert til å ha relevans for utvikling av hammertå: revmatoid artritt, diabetes med perifer nevropati, nevro-

\section{Hovedbudskap}

- Hammertå er den vanligste feilstillingen i småtær

- De fleste som opereres for hammertå er kvinner, og de fleste har høy alder

- $25 \%$ av pasientene som ble operert med subkapital reseksjon av proksimale falang svarte i denne undersøkelsen at de var misfornøyd med resultatet 
logiske sykdommer og komplikasjoner etter skade som rammet underekstremitet. Basert på de innsamlede data var det ikke mulig å gjøre en systematisk gjennomgang av hvilken grad disse bidiagnosene hadde betydning for kirurgens preoperative vurdering. Informasjonen om bidiagnoser ble bare brukt for å klarlegge mulig årsak til hammertå.

Spørsmålene i spørreskjemaet var rettet mot resultatet av operasjonen. Det ble spurt om opererte tå var et problem i dag, om tåen var bedre enn før operasjonen, om de ville latt seg operere hvis de på forhånd hadde vært kjent med resultatet, om de hadde hatt infeksjon etter operasjonen og om hammertåen var reoperert (dette siste for å fange opp reoperasjoner utført ved annen institusjon). Separate skjema ble sendt ut for hver opererte tå med tegning av begge føtter hvor aktuelle tå var avmerket.

De av pasientene som anga vedvarende problem med operert hammertå ble innkalt til klinisk etterkontroll. For de som møtte til slik etterkontroll, ble det fylt ut skjema for å gradere funksjon og akser i operert hammertå (American Orthopaedic Foot \& Ankle Society (AOFAS) lesser toe metatarsophalangeal-interphalangeal scale) (11). På skjemaet graderes smerte, funksjon (mulig aktivitet, type skobehov, bevegelighet i ledd, eventuelle kallositeter) og akser i tær. Ingen smerter gir 40 poeng, normal god funksjon gir 45 poeng, og ingen feilstillinger gir 15 poeng. Originalversjonen av skjemaet gir til sammen 100 poeng (11). Fordi redusert bevegelsesutslag i interfalangnivå er tilsiktet etter hammertåoperasjon, ble punktet for midtleddsbevegelse på skjemaet utelatt, og beste mulig skår var da 85 .

Ved statistisk sammenlikning ble det brukt khikvadrattest for nominelle data. P-verdi mindre enn 0,05 ble regnet som statistisk signifikant.

\section{Resultater}

Svarprosenten var 93. Gjennomsnittsalder ved operasjon var 65 år (spredning 29-88 år), og 86 \% var kvinner. 98 av de 170 opererte tærne var andre tå (tab 1). Til sammen 94 hammertær var operert på høyre side og 76 på venstre. Av bidiagnoser som kan ha innvirkning på utvikling av fotdeformiteter, var revmatoid artritt hyppigst (tab 2). 29 pasienter $(22 \%)$ operert $i$ til sammen 35 tær hadde bidiagnoser som kan bidra til å forklare utvikling av forfotsdeformitet.

Preoperativt ble som regel hammertån beskrevet som fleksjonsstilling i midtleddet med kallositeter over dette. Operasjonsmetoden varierte noe, men alle var operert med en reseksjon av distale del av proksimale falang. På 119 tær var dette gjort alene, men 16 tær var i tillegg pinnefiksert, og i 35 tær ble brusken på midtfalangen også fjernet. 20 pasienter $(12 \%)$ fikk i tillegg til hammertåoperasjon utført en korreksjon av hallux valgus i samme seanse. Det var ingen signifikant forskjell mellom de tre variantene av operasjonsme- tode med hensyn til resultat angitt som subjektive plager i opererte tå $(\mathrm{p}=0,1)(\operatorname{tab} 3)$.

Det ble gjort postoperativ kontroll etter 14 dager ved 110 av de 170 operasjonene. Ved disse tidlige postoperative kontrollene ble det notert komplikasjoner i 32 tær: smerter (12 tær), antibiotikatrengende infeksjon (fem tær), feilstilling (fem tær), plagsom, forbigående hevelse (seks tær) og bekymringsfull feilstilling i stortåen $\mathrm{i}$ fire føtter (disse fire var alle operert for hammertå i andre stråle).

På spørreskjemaet krysset 25 pasienter $(19 \%)$ for at de fortsatt hadde problem med i alt 35 opererte hammertær. 12 pasienter (9\%) svarte at de ikke ville ha latt seg operere om de på forhånd hadde kjent resultatet. Journalgjennomgang viste at 11 av pasientene hadde vært reoperert. Én av disse oppga fortsatt å ha problem med den reopererte tåen. Resultatet var dårlig ved til sammen 43 primære hammertåoperasjoner (25\%). $75 \%$ av pasientene mente at den primære hammertåoperasjonen hadde gitt dem en problemfri tå. Ved oppfølgingstidspunktet var noen pasienter reoperert, slik at andelen som var uten problemer økte til $81 \%$.

25 pasienter, operert i 36 tær, anga vedvarende problemer med operert hammertå. Disse ble innkalt til klinisk etterkontroll. Åtte av dem møtte ikke. De 17 som møtte var operert i 23 tær. Én var kvitt sine plager etter operasjon for Mortons nevralgi. To andre pasienter hadde også etter hammertåoperasjonen utviklet brennende smerter i foten og nummenhet $i$ tær ved bruk av sko som ved Mortons metatarsalgi. Blant de resterende 14 pasientene fant vi hos sju pasienter hyperekstensjonsstilling i grunnleddet i 13 opererte tær, hvorav fem hadde symptomatisk kallositet under grunnleddet. Tre pasienter hadde slark med ny feilstilling i den opererte tåen. Fire pasienter hadde ukorrigert hallux valgus $i$ andre tå, slik at tåen la seg over stortåen. De 17 pasientene som var til etterkontroll, hadde en gjennomsnittsskår på 53 (34-83) på skjemaet AOFAS lesser toe metatarsophalangealinterphalangeal scale (11).

\section{Diskusjon}

Vårt materiale utgjør 131 pasienter som fikk subkapital reseksjon av 170 hammertær. I to andre studier som oppsummerer resultater etter subkapital reseksjon, var materialet på henholdsvis 67 pasienter med 118 opererte hammertær (5) og 78 pasienter med 84 opererte hammertær (12). Det var langt flere kvinner enn menn $i$ vårt materiale $(86 \%)$,
Tabell 1 Fordeling blant 170 opererte hammertær

\begin{tabular}{|cc|} 
& Antall (\%) \\
\hline Andre tå & $97(57)$ \\
\hline Tredje tå & $35(21)$ \\
\hline Fjerde tå & $27(16)$ \\
\hline Femte tå & $11(6)$ \\
\hline
\end{tabular}

Tabell 2 Bidiagnoser med mulig innvirk ning på forfotsdeformiteten i operert tå

\begin{tabular}{lc} 
& Antall \\
\hline Revmatoid artritt & 24 \\
\hline Diabetes med perifer nevropati & 5 \\
\hline Nevrologisk sykdom & 4 \\
\hline Komplikasjon etter skade & 2 \\
\hline
\end{tabular}

noe man også ser i andre studier (75-99\% kvinner) $(1,4,5,13)$. Bruk av sko med høy hæl som gir hyperekstensjon av proksimale falang gjennom hele gangsyklusen, har vært antatt som hyppigste årsak til kvinnedominansen $(1,14-16)$.

Vi fant at $22 \%$ av pasientene hadde bidiagnoser som kan bidra til å forklare utvikling av hammertå. Dette er imidlertid svært usikre data, da studien er retrospektiv og opplysninger om relevante bidiagnoser kan ha gått tapt. Gjennomsnittsalderen $i$ vårt materiale ved operasjonstidspunktet var 65 år, noe som også er i samsvar med tidligere publiserte studier av hammertær $(1,4)$. Blant våre pasienter var over halvparten av alle hammertær operert i andre stråle (58 \%). Også i andre studier ser vi at denne tåen er den som oftest må opereres, med henholdsvis $35 \%$ og $45 \%$ av opererte hammertær $(5,13)$.

Ved den kliniske etterkontrollen av pasienter med fortsatt problemer i operert tå hadde to av pasientene utviklet metatarsalgi, med brennende smerter $\mathrm{i}$ foten og nummenhet $\mathrm{i}$ tær ved bruk av sko. Én pasient, som opprinnelig hadde beskrevet hammertåen som problematisk, var blitt smertefri etter en operasjon for Mortons metatarsalgi. Om metatarsalgi er en komplikasjon til selve hammertåinngrepet, er usikkert. I én studie har man beskrevet metatarsalgi med smerter og nummenhet som en komplikasjon etter hammertåoperasjoner (8). I andre studier har antallet tilfredse pasienter etter samme operasjon for hammertær variert. $84 \%$ var tilfredse i
Tabell 3 Antall hammertær operert med reseksjon av proksimale falang som fortsatt gir subjektive plager, relatert til variant av operasjonsmetoden

\begin{tabular}{|lccc} 
& $\begin{array}{c}\text { Kun subkapital } \\
\text { reseksjon }\end{array}$ & $\begin{array}{c}\text { Subkapital reseksjon } \\
\text { og reseksjon } \\
\text { av brusk i midtfalang }\end{array}$ & $\begin{array}{c}\text { Subkapital reseksjon } \\
\text { og pinnefiksasjon }\end{array}$ \\
\hline Totalt antall opererte tær & 119 & 35 & 16 \\
\hline Fortsatt plager i operert tå & $26(21 \%)$ & $4(11 \%)$ & $5(31 \%)$
\end{tabular}


Coughlin og medarbeideres studie (5). Cahill\& Connor viser i sin studie (12) at sju av de 34 pasientene som møtte til etterkontroll var misfornøyde med operasjonsresultatet (noe som tilsier $79 \%$ fornøyde), men ut fra objektive kriterier, slik som akser og form på tærne og fravær av kallositeter og metatarsalgi, var suksessraten $50 \%$. Lehman \& Smith fant $i$ en retrospektiv undersøkelse som evaluerte hammertåoperasjoner der det var gjort en formell artrodese i mellomleddet, at $85 \%$ ville latt seg operere på nytt hvis de hadde kjent til operasjonsresultatet på forhånd (10).

Vi fant ingen signifikant forskjell mellom de tre forskjellige operasjonsvariantene av subkapital reseksjon av proksimale falang som er gjort i denne studien, men prosentfordelingen av misfornøyde pasienter blant dem som fikk fjernet brusken på begge sider i det proksimale interfalangealleddet og derigjennom tillot en artrodeseutvikling, var mindre enn ved de to andre variantene (tab 3 ). Blant de 17 misfornøyde pasientene som møtte til klinisk etterkontroll $\mathrm{i}$ vår studie, fant vi at årsaken til misnøyen var en hyperekstensjonsstilling i grunnleddet $\mathrm{i}$ den opererte tåen hos sju pasienter (41\%). En slik hyperekstensjonstilling i grunnleddet er en mer omfattende feilstilling enn en hammertå. Vi vet ikke sikkert om denne stillingen også var til stede preoperativt, men i så fall burde den ha vært korrigert med bløtdelsløsning $(5,17,18)$.

Vi mener at andelen misfornøyde pasienter i denne studien er for høy. Inntrykket er at noen tær med hyperekstensjonsstilling $\mathrm{i}$ grunnleddet feilaktig har vært tolket som enkel hammertå og at det derfor ikke ble gjort bløtdelsløsning rundt grunnleddet. Ved bedre preoperativ differensiering av «krøllete» tær håper vi at andelen misfornøyde pasienter kan reduseres. Vi vil også vurdere om en reell artrodese i mellomleddet er en bedre operasjonsmetode for hammertå enn bare en subkapital reseksjon i proksimale falang.

Oppgitte interessekonflikter: Ingen

\section{Litteratur}

1. Coughlin MJ, Thompson FM. The high price of high-fashion footwear. Instr Course Lect 1995; 44: $371-7$.

2. Schlefman BS, Fenton CF 3rd, McGlamry ED. Peg in hole arthrodesis. J Am Podiatry Assoc 1983: 73 . 187-95.

3. Sivard T, Hansen JR. Functional reconstruction of the foot and ankle. Philadelphia, PA: Lippincott WilliamsWilkins, 2000

4. Cameron HU, Fedorkow DM. Revision rates in forefoot surgery. Foot Ankle 1982; 3: 47-9.

5. Coughlin MJ, Dorris J, Polk E. Operative repair of the fixed hammertoe deformity. Foot Ankle Int 2000: 21:94-104.

6. Brevig K, Barbari SG. Klotær behandlet med senetransposisjon. Tidsskr Nor Lægeforen 1985; 105 $581-4$.

7. Coughlin MJ. Mallet toes, hammer toes, claw toes, and corns. Causes and treatment of lesser-toe deformities. Postgrad Med 1984; 75: 191-8.

8. Newman RJ, Fitton JM. An evaluation of operative procedures in the treatment of hammer toe. Acta Orthop Scand 1979: 50: 709-12.

9. Cracchiolo A 3rd, Kitaoka HB, Leventen EO. Silicone implant arthroplasty for second metatarso- phalangeal joint disorders with and without hallux valgus deformities. Foot Ankle 1988; 9: 10-8.

10. Lehman DE, Smith RW. Treatment of symptomatic hammertoe with a proximal interphalangeal joint arthrodesis. Foot Ankle Int 1995; 16: 535-41.

11. Kitaoka HB, Alexander IJ, Adelaar RS et al. Clinical rating systems for the ankle-hindfoot, midfoot, hallux, and lesser toes. Foot Ankle Int 1994; 15: 349-53.

12. Cahill BR, Connor DE. A long-term follow-up on proximal phalangectomy for hammer toes. Clin Orthop Relat Res 1972; 86: 191-2.

13. Reece AT, Stone MH, Young AB. Toe fusion using Kirschner wire. A study of post- operative infection rate and related problems. J R Coll Surg Edinb 1987; 32: 157-9.

14. Coughlin MJ. Lesser toe deformities. Orthopedics 1987; 10: 63-75.

15. Coughlin MJ. Subluxation and dislocation of the second metatarsophalangeal joint. Orthop Clin North Am 1989; 20: 535-51.

16. Scheck M. Etiology of acquired hammer toe deformity. Clin Orthop Relat Res 1977; 123: 59-63.

17. Coughlin MJ. Common causes of pain in the forefoot in adults. J Bone Joint Surg Br 2000; 82: $781-90$.

18. Fortin PT, Myerson MS. Second metatarsophalangeal joint instability. Foot Ankle Int 1995; 16: 306-13.

Manuskriptet ble mottatt 11.7. 2009 og godkjent 9.9. 2010. Medisinsk redaktør Are Brean. 